\title{
CONHECIMENTOS E OPINIÕES DOS TRABALHADORES SOBRE O USO E ABUSO DE ÁLCOOL
}

\author{
Knowledge and Opinions of the Workers \\ about the Use and Abuse of Alcohol \\ Conocimientos y Opiniones de los Trabaj adores \\ sobre el Uso y Abuso de Alcohol
}

Fernanda Ferreira da Fonseca ${ }^{1}$

\begin{abstract}
Resumo
Trata-se de um estudo descritivo-exploratório, desenvolvido e fundamentado na abordagem qualitativa. 0 estudo tem como objetivo analisar o conhecimento e as opiniões dos trabalhadores acerca do uso e abuso de álcool, visando à elaboração de um programa de promoção da saúde no trabalho e prevenção de acidentes relacionados ao uso abusivo dessa substância. Para coleta de dados, foram realizadas entrevistas semi-estruturadas com 15 trabalhadores que buscaram atendimento em uma Unidade de Saúde da Família através da consulta de enfermagem. Por meio destas entrevistas, chegou-se à conclusão de que, em geral, os trabalhadores têm pouco conhecimento acerca dos perigos provocados pelo uso abusivo de álcool no trabalho e que é preciso investir em programas de prevenção de acidentes de trabalho causados pelo uso excessivo desta substância, levando-se em consideração o número cada vez maior de casos ocorridos.
\end{abstract}

Palavras-chave: Prevenção de Acidentes. Alcoolismo. Saúde do Trabalhador.

\begin{abstract}
Descriptive and exploratory study developed and based on the qualitative approach. The study has as objective to analyze the knowledge and opinions of the workers concerning the use and abuse of alcohol, aiming at the elaboration of a program of promotion of the health in the work and prevention of related accidents to the abusive use of this substance. For the collection of data, was made a half-structuralized interview with 15 workers who had searched attendance in a Unit of Health of the Family through the nursing consultation. By these interviews it was concluded that in general the workers have little knowledge about the danger provoked by the abusive alcohol use in the work and that is necessary to invest in programs of prevention of accidents caused by the extreme use of this substance, taking in consideration the large number of cases occurred.
\end{abstract}

Keywords:

Accident Prevention. Alcoholism. Occupational Health.

\section{Resumen}

Estudio descriptivo, exploratorio, desarrollado y basado en el abordaje cualitativo. El estudio tiene como objetivo para analizar el conocimiento y las opiniones de los trabajadores referentes al uso y abuso del alcohol, visando la elaboración de un programa de promoción de salud en el trabajo y prevención de accidentes relacionados al uso abusivo de esta sustancia. La colecta de datos envolvió entrevistas semiestructuradas con 15 trabajadores que habían buscado atención en una Unidad de Salud de la Familia a través de la consulta de enfermería. Por medio de estas entrevistas, se llegó a conclusión de que, en general, los trabajadores tienen poco conocimiento referente a los peligros provocados por el uso abusivo del alcohol en el trabajo y que es necessario invertir en programas de prevención de los accidentes de trabajo causados por el uso extremo de esta sustancia, llevandose en consideración el numero cada vez mayor de casos ocurridos.

Palabras clave:

Prevención de Accidentes. Alcoholismo. Salud Laboral. 


\section{INTRODUÇÃO}

0 presente estudo tem como objetivo analisar o conhecimento e as opiniões dos trabalhadores acerca do uso e abuso de álcool, visando à elaboração de um programa de promoção da saúde no trabalho e prevenção de riscos relacionados ao uso abusivo dessa substância.

0 crescente consumo de álcool e suas devastadoras conseqüências tornaram-se um dos problemas mais graves dos dias atuais. 0 número de pessoas que se tornam dependentes e que são gradativamente destruídas por essa substância aumenta assustadoramente a cada dia. 0 abuso de álcool verificado nos últimos anos e suas conseqüências na vida do indivíduo e da sociedade são considerados hoje um problema de saúde pública ${ }^{1}$.

0 uso abusivo de álcool constitui, na atualidade, uma ameaça à humanidade e à estabilidade das estruturas do Estado e da sociedade. Suas conseqüências afetam a todos os espaços geográficos, incluindo todos os indivíduos, independentemente da classe social e econômica². Isso faz com que haja uma preocupação cada vez maior por parte das famílias, profissionais de saúde e de educação e autoridades governamentais quanto ao crescente número de alcoolistas no país.

0 problema tem se espalhado nas sociedades industrializadas, atingindo dimensões epidêmicas, transformando-se num sintoma inquietante de um novo e profundo mal-estar na civilização e trazendo sérias conseqüências não só no que diz respeito à saúde, como também aos grandes gastos financeiros para os governos.

0 alcoolismo e as doenças orgânicas associadas ao álcool constituem uma das principais causas de internação no Brasil. Também nos hospitais psiquiátricos, o alcoolismo tem sido apontado como a causa mais freqüente de internação com números variando entre $19 \%$ e $50 \%$, dependendo do estudo ${ }^{3}$.

Trata-se de uma questão que acomete principalmente os grupos mais jovens e também os adultos que trabalham, nos quais as conseqüências podem ser fatais, dada a possibilidade dos acidentes de trabalho, afetando, também, a produtividade das empresas. Seus graves efeitos se estendem também à questão social e familiar, esta última tendo em vista a desestruturação da família, inclusive no aspecto econômico, uma vez que grandes quantias de dinheiro são gastas pelos trabalhadores no consumo de bebidas.

Em 1948, a Organização Mundial da Saúde incluiu o alcoolismo como um item diferenciado da intoxicação alcoólica e psicoses alcoólicas, na Classificação Internacional de Doenças (CID). Atualmente o alcoolismo encontra-se classificado pela CID na sua $10^{a}$ revisão, no capítulo referente aos transtornos mentais e de comportamento.

0 trabalho é considerado um dos fatores psicossociais de risco para o alcoolismo crônico ${ }^{4} .0$ consumo coletivo de bebidas alcoólicas associadas a situações de trabalho pode ser decorrente de prática defensiva, como meio de garantir inclusão no grupo. Também pode ser uma forma de viabilizar o próprio trabalho, em decorrência dos efeitos farmacológicos próprios do álcool: calmante, euforizante, estimulante, relaxante, indutor do sono, anestésico e anti-séptico
0 uso de álcool existe cada vez mais entre pessoas incorporadas à vida produtiva, trazendo como conseqüências a diminuição da produtividade, alterações das relações na ordem laboral, interpessoal, familiar, social e da saúde.

0 estímulo para discutir essa temática emergiu da prática na condição de enfermeira inserida na Estratégia Saúde da Família no Município de São Pedro da Aldeia no Rio de Janeiro. Nesse contexto, tenho acompanhado, através da consulta de enfermagem, um número cada vez maior de trabalhadores que fazem uso abusivo de álcool e, não raro, tornam-se vítimas de acidentes de trabalho.

A Estratégia Saúde da Família trata-se de um novo modelo de assistência à saúde que visa à reorganização da Atenção Básica no país de acordo com os princípios do SUS. Uma das características do processo de trabalho das equipes de Atenção Básica comum à Estratégia Saúde da Família é o desenvolvimento de ações focalizadas sobre grupos de risco e fatores de risco comportamentais com a finalidade de prevenir o aparecimento ou a manutenção de doenças e danos evitáveis.

A partir deste enfoque, o presente estudo tem como objetivo analisar o conhecimento, opiniões e expectativas dos trabalhadores acerca do uso e abuso de álcool, visando à elaboração de um programa de promoção da saúde no trabalho e prevenção de riscos relacionados ao uso abusivo dessa substância.

A pesquisa torna-se relevante uma vez que se apóia na necessidade de produzir conhecimento científico e prático relacionado ao fenômeno "uso e abuso de álcool no trabalho". Além disso, o estudo pretende trazer para a comunidade científica novos conteúdos, através do levantamento de informações sobre o conhecimento e opiniões dos trabalhadores acerca dessa temática. Pretende-se contribuir também com o próprio trabalhador, buscando fortalecer a participação do mesmo na elaboração de um "programa participativo", trazendo-lhe maior segurança profissional e valorização pessoal.

\section{TEORIZANDO SOBRE O ALCOOLISMO E O TRABALHADOR}

0 alcoolismo refere-se a um modo crônico e continuado de usar bebidas alcoólicas, caracterizado pelo descontrole periódico da ingestão ou por um padrão de consumo de álcool com episódios freqüentes de intoxicação e preocupação com 0 álcool e seu uso, apesar das consequêencias adversas desse comportamento para a vida e a saúde do usuário 4 .

Segundo a Organização Mundial de Saúde, a síndrome de dependência do álcool é um dos problemas relacionados ao trabalho. A Sociedade Americana das Dependências em 1990 considerou o alcoolismo como uma doença crônica primária que tem seu desenvolvimento e manifestações influenciadas por fatores genéticos, psicossociais e ambientais, freqüentemente progressiva e fatal.

0 álcool é considerado a substância de uso mais comum tanto na perspectiva da Saúde Pública como, particularmente, na Saúde do Trabalhador. No Brasil, a Associação dos Estudos do Álcool e outras Drogas estimou, em 1990, que o alcoolismo é o terceiro motivo de absenteísmo no trabalho, sendo a causa mais freqüente de aposentadoria precoce e acidentes de trabalho, e a oitava causa para concessão de auxílio doença pela Previdência Social. 
Hoje o trabalho tem um papel fundamental para os indivíduos no mundo. Contribui para a formação da sua identidade e permite que os indivíduos participem da vida social como elemento essencial para a saúde ${ }^{5}$, daí a necessidade de se conhecerem os fatores que interferem na qualidade de vida e no trabalho. Cada categoria profissional tem suas especificidades ligadas ao seu passado histórico, ao nível de organização e combatividade nas conquistas incorporadas à legislação, ao sistema repressivo explícito à que está sujeita e aos fatores nocivos envolvidos especificamente na atividade laboral'.

É importante salientar, no conjunto de fatores de risco associados à etiologia multicausal do alcoolismo crônico, que a própria ocupação desenvolvida pelo trabalhador pode ser considerada como fator de risco. As profissões de maior risco são aquelas em que os indivíduos trabalham por muitas horas seguidas, em trabalhos noturnos ou que exijam constante vigilância, e em que os profissionais atuam em ambiente de grande estresse ${ }^{7}$. Também os trabalhadores de saúde se enquadram na questão do risco devido a um alto índice de ansiedade, relacionado ao próprio trabalho, o que os leva a buscar mecanismos compensatórios.

Além disso, há uma grande freqüência de casos (individuais) de alcoolismo observada em ocupações que se caracterizam por serem socialmente desprestigiadas e mesmo determinantes de certa rejeição, como as que implicam contatos com cadáveres, lixo ou dejetos em geral, apreensão e sacrifício de cães; atividades em que a tensão é constante e elevada; de trabalho monótono em que a pessoa trabalha em isolamento do convívio humano (vigias) e situações de trabalho que envolvem afastamento prolongado do lar (viagens freqüentes, plataformas marítimas, zonas de mineração) ${ }^{4}$.

Porém, estudos mais recentes indicam que, no Brasil, atualmente o maior consumo de álcool ocorre no primeiro escalão das empresas (dirigentes e altos executivos), tendo como justificativas a necessidade de reduzir o estresse decorrente da competitividade 8 .

Devido à extensão do problema e suas graves conseqüências, as autoridades governamentais recomendam prioridade nas ações de combate ao alcoolismo, com o objetivo de diminuir os agravos à saúde do trabalhador e os acidentes de trabalho, em destaque os programas de prevenção e promoção da saúde que têm por objetivo identificar situações de alcoolismo ou tendências a ele.

Priorizar a prevenção do uso indevido de drogas e álcool no setor de trabalho é uma intervenção eficaz e de menor custo para a sociedade. Nesse contexto, a equipe de enfermagem, como parte da equipe de saúde, desenvolve em papel importante para ajudar os indivíduos a manter sua saúde. A equipe de enfermagem deverá estar empenhada em promover, manter e restabelecer a saúde do trabalhador. A promoção de saúde desenvolve estratégias no sentido de valorizá-la, visando reduzir os riscos relacionados com a saúde do trabalhador e, conseqüentemente, preservar a integridade e satisfação no trabalho além da mais alta produtividade ${ }^{9}$.

De acordo com o Programa Nacional Antidrogas (PNAD) ${ }^{2}$, no ambiente de trabalho, as doenças relacionadas com o uso e abuso de álcool e drogas trazem como conseqüência o absenteísmo, custos diretos e indiretos decorrentes do uso dessas substâncias, acidentes e/ou aumento do risco de acidentes, diminuição da produtividade, aumento de conflitos de grupo e problemas interpessoais com os companheiros de trabalho.

Esta realidade complexa em que, de um dia para o outro, o trabalhador é incapacitado ou limitado por um acidente ou por outros motivos de saúde para desempenhar suas funções na empresa, tornase uma questão de grande relevância. Se o trabalhador se ausenta freqüentemente do trabalho ou quando retorna não pode levar adiante as funções adequadamente, ou não atende às exigências de produtividade, estes fatos provocam transtornos e perdas para a organização e devem ser esclarecidos para serem tratados.

Alguns fatores contribuem para que o consumo de bebida alcoólica venha aumentando significativamente nos últimos anos. É possível destacar a valorização do álcool reproduzida pela mídia como objeto intermediário nas relações sociais, na qual são exibidos altos executivos tomando um drink para relaxar após uma importante reunião, ou aqueles grandes amigos que, após o trabalho, se sentam à mesa de um bar para comemorar algum evento, ocasião na qual não pode faltar a bebida alcoólica para intermediar a alegria daquele momento. Além disso, os próprios atrativos naturais do álcool, como o sabor e o efeito euforizante, quando ele é consumido em pequenas doses, facilitam a inserção do indivíduo na cultura consumidora desta substância.

Algumas culturas seguem regras predeterminadas para 0 consumo do álcool ou têm rituais estabelecidos de onde, quando e como beber. Assim sendo, têm menores taxas de uso abusivo de álcool quando comparadas com outras que não seguem qualquer padrão. No entanto, no Brasil, o indivíduo abstêmio pode chegar a ser discriminado diante da recusa na parceria nas rodadas alcoólicas com amigos. Isso faz com que a bebida seja dificilmente dissociada da vida das pessoas, inclusive dos trabalhadores ${ }^{10}$.

Podemos ainda identificar fatores psicossociais negativos relacionados ao trabalho como determinantes de risco ao desenvolvimento do alcoolismo; dentre eles, Donato ${ }^{10: 25}$ destaca:

...o inadequado desenvolvimento e aproveitamento dos potenciais, a sobrecarga de trabalho, a insegurança profissional, a desigualdade no salário, os erros dos supervisores, as relações conflituosas no trabalho, a falta de reconhecimento profissional, a frustração quanto à realização de projetos de vida $e$ ao aumento da qualidade de vida, o trabalho executado em turnos e o perigo físico.

Diante da complexidade e da diversidade de fatores de risco que podem levar o trabalhador ao alcoolismo, acredito que programas devem ser desenvolvidos com a finalidade de atendimento aos trabalhadores que fazem uso abusivo de álcool e de prevenção visando àqueles que não consomem a substância. Estes programas devem ser criados sob um olhar amplo, de forma que sejam analisados os fatores multicausais que podem levar ao alcoolismo. Através desse olhar, serão mais fáceis a compreensão da doença e a adesão do paciente aos programas, tornando a prevenção do risco de acidente de trabalho uma meta a ser alcançada mais facilmente. 


\section{METODOLOGIA}

Trata-se de um estudo descritivo-exploratório, sendo desenvolvido e fundamentado na abordagem qualitativa, por melhor adequar-se à análise do objeto e alcance dos objetivos. A pesquisa qualitativa é aquela em que se trabalha com 0 universo de significados, motivos, aspirações, crenças, valores e atitudes, o que corresponde a um espaço mais profundo das relações, dos processos e dos fenômenos ${ }^{11}$. Por esse motivo, esse tipo de abordagem veio perfeitamente ao encontro da perspectiva de alcançar os objetivos da pesquisa.

Os sujeitos desta pesquisa foram trabalhadores que buscaram atendimento médico e que passaram pela consulta de enfermagem em uma Unidade de Saúde da Família no Município de São Pedro da Aldeia, Região dos Lagos, Rio de Janeiro. Totalizaram um número de 15 trabalhadores entrevistados, sem haver planejamento prévio quanto ao número de participantes.

0 interesse da pesquisa qualitativa não está focalizado em contar o número de vezes que a variável aparece, mas sim que qualidade elas apresentam, não sendo necessário definir previamente o número de entrevistados. A decisão de encerrar a coleta de dados é tomada quando o pesquisador percebe que as informações colhidas até o momento são suficientes para atender os intuitos do estudo ${ }^{12}$.

Ressalto que nessa ocasião os sujeitos procuraram a Unidade com queixas diversas e foram escolhidos aleatoriamente conforme aceitavam participar da entrevista. Os depoimentos foram obtidos por meio de entrevista semiestruturada com o uso de gravador. Dessa forma, entendo que foi possível permitir ao sujeito pensar e produzir respostas livres, além de tornar opor tuno o estabelecimento de uma relação dialógica com o entrevistado.

A coleta de dados tomou por base três questões norteadoras: "Que informações os trabalhadores têm acerca do fenômeno uso e abuso de álcool?", "Quais os fatores de risco relacionados ao abuso de álcool no trabalho?" e "Como o conhecimento, opiniões e expectativas dos trabalhadores acerca do uso e abuso do álcool podem contribuir para a elaboração de um programa de prevenção ao alcoolismo?".

Os trabalhadores foram esclarecidos quanto aos objetivos da pesquisa e assegurados de que teriam sua identidade preservada. Todos assinaram um Termo de Consentimento Livre e Esclarecido, respeitadas as determinações que constam na Resolução 196/ 96, do Conselho Nacional de Pesquisa em Saúde, que dispõem sobre diretrizes e normas regulamentadoras de pesquisa envolvendo seres humanos - CONEP.

A coleta de dados iniciou-se após se obter o consentimento dos participantes. Cabe ressaltar que, ao iniciar as entrevistas, foi esclarecido aos participantes a necessidade do uso do gravador para facilitar o registro, na íntegra, dos depoimentos e sua posterior transcrição.

As informações foram trabalhadas por meio de análise temática, a qual propicia conhecer uma realidade por meio das comunicações de indivíduos que tenham vínculo com a mesma. Como resultado, emergiram quatro unidades temáticas, denominadas: 0 alcoolismo como "um problema dos outros"; alcoolismo como fator de risco no trabalho; alcoolismo como doença; e sentimentos confessados: a dependência ao álcool.

\section{APRESENTAÇÃO E DISCUSSÃO DOS DADOS}

\section{O alcoolismo como "um problema dos outros"}

Durante as entrevistas, alguns sujeitos reconheceram que o alcoolismo é um problema, porém o vêem como algo que não os prejudicaria apesar de fazerem uso de bebida alcoólica.

... esse negócio de alcoolismo é para gente fraca que não sabe beber. Eu sempre bebi e nunca fiquei "ruim", pelo contrário, fico até mais alegre. (E1)

Conheço um cara que é alcoólatra. Ele já acorda bebendo cachaça... Não é o meu caso. Eu bebo só pra descontrair... (E8)

De acordo com essas falas, pode-se observar que existe uma certa banalização do tema. Os entrevistados parecem ver o alcoolismo como algo distante de si, apesar de fazerem uso da substância com alguma freqüência. Além disso, podem-se perceber distorç̃es do pensamento, em alguns casos evidenciando a negação, isto é, o bebedor alcoólico tende a não reconhecer que faz uso abusivo do álcool. Mais da metade dos pacientes com problemas relacionados ao álcool não é identificada. Somando-se o subdiagnóstico, o preconceito e obstáculos em motivar o paciente para o processo de mudança de comportamento, o resultado é a enorme dificuldade no diagnóstico e tratamento ${ }^{10}$. Outro discurso que revelou o uso do álcool pelo sujeito e seu conhecimento acerca disto:

Não tenho o hábito de beber todos os dias, mas no final de semana tem que ter uma cervejinha para relaxar ... tem gente que não consegue parar, acho que isso que é alcoolismo ... mas eu sei a hora de parar. (E5)

Neste relato, observamos que o sujeito demonstra conhecer que o uso do álcool leva à dependência, porém não reconhece em si mesmo o risco, embora também faça uso da substância.

Atualmente, $84 \%$ da população brasileira apresentam crescente consumo ocasional do álcool e, no mínimo, 3\% a $10 \%$ destes terão início de cronicidade pela bebida.

É importante lembrar que o consumo de álcool em qualquer volume deve sempre ser evitado ao máximo como medida preventiva, pois étênue o limite entre ouso e o abuso esuas graves consequiências, também se for levado em conta o fato de que o alcoolismo é uma doença insidiosa, de evolução lenta e quase despercebid ${ }^{10}$.

0 indivíduo que faz uso de bebida alcoólica, até chegar à dependência, passa por um processo de evolução da doença que possui várias fases, e uma delas é exatamente aquela em que a pessoa tem o primeiro contato com o álcool. À medida que o uso esporádico dessa substância vai se tornando uma rotina, aos poucos a bebida passa a fazer parte de sua vida. Ela está presente nas comemorações, nas reuniões com os amigos, enfim, lentamente 0 álcool vai se tornando parte indissociável da vida das pessoas. A partir daí, o risco para dependência vai se tornando gradativamente maior.

Portanto, não reconhecer em si mesmo que o uso da bebida alcoólica, mesmo que esporádico a princípio, pode levar à dependência trata-se de uma séria questão, pois grande parte desses usuários se tornará alcoolista com o tempo. Em se tratando de trabalhadores, ressalto a questão do risco para acidentes de trabalho como um fato que deve ser levado em consideração. 


\section{Alcoolismo como fator de risco no trabalho}

Alguns sujeitos fizeram colocações expressivas quanto ao risco que o alcoolismo representa para o trabalhador durante o desenvolvimento de suas funções:

Acho que, se o cara estiver trabalhando alcoolizado, ele corre o risco de cometer erros ... dependendo do trabalho que ele faz, isso pode até representar risco de vida ... risco de vida dele e às vezes de outras pessoas também.(E11)

A afirmativa deste trabalhador corresponde a uma realidade. De acordo com dados do Programa Nacional Antidrogas $2001^{2}$, o uso de drogas e álcool aumenta em cinco vezes as chances de acidentes de trabalho, relacionando-se com $5 \%$ a $13 \%$ das ocorrências. Sabe-se que no sistema nervoso dos alcoolistas ocorre perda da identidade total ou parcial e do domínio dos próprios movimentos na embriaguez. Isso quer dizer que o risco aumenta significativamente nesse estado. Trabalhadores que atuam diretamente operando máquinas ou dirigindo carros, ônibus ou caminhões, por exemplo, colocam não só suas vidas em risco, mas também a de outras pessoas que possam com ele estar envolvidas naquele momento.

Pra falar a verdade, eu mesmo tive um problema... eu dirigia ônibus e um final de semana eu exagerei na cerveja... era um aniversário ... perdi o controle do coletivo e bati. Não era pra mim beber naquele dia, eu assumo o meu erro.

De acordo com esse relato, é possível perceber que 0 trabalhador se expôs ao risco mesmo tendo consciência dele. Os trabalhadores podem até desafiar o perigo e construir o que é chamado de "ideologia defensiva" como mecanismo coletivo de proteção contra o medo ${ }^{14}$. Esta é uma estratégia segundo a qual, diante de atividades reconhecidamente arriscadas, os trabalhadores tendem a desafiar o perigo se expondo a ele. Ao desafiarem o risco, eles teriam a sensação de dominá-lo. No entanto, tendo o sujeito feito uso excessivo de álcool, ocorre um agravante, pois, além da exposição ao risco ligada à profissão, o trabalhador sob efeito do álcool perde a capacidade de conduzir com segurança seu instrumento de trabalho, aumentando a possibilidade da ocorrência de um acidente. Apesar deste fato, o trabalhador, algumas vezes, só reconhece o risco após ter passado pelo acidente, e programas preventivos de esclarecimento podem ser úteis nesse aspecto.

\section{Alcoolismo como doença}

$\mathrm{Na}$ construção deste tema, percebe-se a presença da palavra doença colocada pelos sujeitos e apresentada como algo de certa forma desprezível. Ao mesmo tempo, vêem o alcoolista com certo preconceito, vítima de uma doença causada por ele mesmo devido à sua "fraqueza".

Alcoolismo éuma doença. O cara que éalcoólatra éum cara doente, que tem que se tratar ... isso aí é uma fraqueza que ele tem pela bebida. Eu não bebo nem por distração... (E2)

Observa-se aqui que o sujeito reconhece o alcoolismo como uma doença. 0 que é uma realidade, conforme classificação na décima edição do Código Internacional de Doenças (CID 10), onde podemos encontrá-lo caracterizado como doença crônica, conforme já foi citado anteriormente. No entanto, nota-se também nas afirmações geradas pelos sujeitos traços de preconceito pelo indivíduo alcoolista.

0 desprezo percebido nessas afirmações pode ter relação com representações negativas geradas na sociedade relacionadas com o indivíduo que faz uso abusivo de álcool. A visão de que o alcoolista é alguém fraco o torna socialmente rejeitado. Os sujeitos que assim vêem o alcoolismo também 0 fazem por terem uma vivência anterior com o problema que foi negativa; experiências vividas com pessoas conhecidas, e até familiares, trazem à lembrança acontecimentos desagradáveis que geram cer to desprezo pelo tema. 0 alcoolismo é tido como uma doença familiar, capaz de prejudicar a saúde física e emocional de qualquer membro da família' ${ }^{13}$. 0 uso da substância etílica traz impactos diretos sobre o cônjuge e os filhos em termos físicos, psicológicos e de imagem social dos papéis com que desempenham suas funções. Os prejuízos poderão ainda se apresentar através das questões financeiras, rendimento escolar, entre outros.

A crise da família pode representar uma incubadora onde se desenvolve o risco da droga e do álcool, porque a falta de afetividade e relacionamento familiar difícil ou desestruturado entre seus membros podem levar à fuga sem volta para 0 alcoolismo ou outras formas de drogadiçãa $0^{15}$.

Alcoolismo é uma doença. A pessoa que começa a beber tem que saber que depois não vai conseguir parar... conheço gente que tem esse problema, mas eu mesmo não gosto nem do cheiro da bebida...(E10)

Nesta afirmação, é possível identificar a definição do alcoolismo como doença mais uma vez, contudo, o sujeito coloca o problema como algo sem solução, uma doença incurável quando diz: "depois não vai conseguir parar", evidenciando seu desconhecimento a respeito do problema. Sabe-se que o alcoolismo é uma doença perfeitamente tratável e curável quando acompanhada adequadamente. No entanto, trata-se de uma doença crônica que ainda não tem respostas únicas e certas de tratamento a partir do modelo puramente biomédico.

Ainda assim, o alcoolista devidamente acompanhado pode livrar-se da dependência. Para que isso aconteça, é necessário que o cliente tenha garantido o acesso a um serviço de saúde especializado, em que poderá ser acompanhado por uma equipe multidisciplinar com uma abordagem ampliada de saúde, onde não apenas o problema do alcoolismo será contemplado, mas também questões sociais, econômicas e culturais deste indivíduo que podem influenciar tanto positivamente quanto negativamente no seu tratamento e na recuperação.

\section{Sentimentos confessados: a dependência do álcool}

Durante as entrevistas, um dos sujeitos relatou sua posição como alcoolista, que reconhece seu problema e está em tratamento:

Já tive problema com esse negócio aí. Já perdi até o emprego uma vez por causa disso... mas aprendi a lição 
... Tô me tratando no CAPS... é uma doença muito difícil... Perdi amigos, o trabalho, pessoas da família não confiam mais em mim ... Mas eu vou mostrar pra todo mundo que agora eu tô diferente... as coisas mudaram"(E4)

Entre os fatores que levam à dependência, destacam-se os fatores culturais, pelos quais o indivíduo é valorizado por aquilo que tem, e não por aquilo que é, pois vivemos numa cultura capitalista, consumista, onde o "descartável" se faz presente. No dia-a-dia tudo se torna descartável ou pode deteriorar-se: as relações, os compromissos, as cotidianas responsabilidades, 0 caráter e os valores dos seres humanos ${ }^{15}$.

Também nesse sentido, sabe-se que há uma porcentagem estável de $13 \%$ de pessoas que fazem uso de álcool e se transformam em dependentes. Mas a concepção psicologicamente determinada para a etiologia do alcoolismo coexiste também com a teoria da vulnerabilidade biológica ${ }^{8}$.

Dessa forma, entendo que existe uma série de fatores que tornam alguns indivíduos mais suscetíveis ao alcoolismo do que outros por diversas razões, o que faz afirmar que o indivíduo alcoolista ser chamado de "fraco" é um preconceito social. Muitos estudos surgem nos dias atuais, nos quais a concepção médica da doença alcoolismo se acresce a uma multicausalidade, considerando os fatores de vulnerabilidade genéticos, biológicos, psicológicos, sociais, culturais, políticos e ideológicos, que podem estar, numa visão sistêmica, interagindo ou não na realização do diagnóstico de alcoolismo.

\section{CONSIDERAÇÕES FINAIS}

Com este estudo, chegou-se à conclusão de que os trabalhadores em geral têm pouco conhecimento acerca dos riscos do uso abusivo de álcool, que pode levar à dependência

\section{Referências}

1. Caldeira FZ. Drogas, indivíduo e família: um estudo das relações singulares [dissertação de mestrado]. Rio de Janeiro (RJ): ENSP/FIOCRUZ; 1999.

2. Ministério da Justiça (BR). Programa Nacional Antidrogas-PNAD. Brasília (DF); 2001.

3. Ferreira MJ. Saúde no trabalho. São Paulo(SP): Roca; 2000.

4. Ministério da Saúde (BR). Doenças relacionadas ao trabalho. Manual de Procedimentos para os Serviços de Saúde. $1^{\text {a}} e d$. Brasilia(DF); 2001.

5. Mendes R, Dias EC. Saúde dos trabalhadores. In: Rouquayrol MZ, et al. Epidemiologia e saúde. Rio de Janeiro(RJ): Medsi; 1999.

6. Haag GS, Lopes MJM, Schuck JS, organizadoras. A enfermagem e a saúde dos trabalhadores. Goiânia (G0): AB; 2001.

7. Monteiro M. Sinal de alerta. Rio de Janeiro(RJ); 2000.

8. Donato M. Reinserção do trabalhador alcoolista no contexto laboral: a percepção do enfermeiro do trabalho [tese de doutorado]. Rio de Janeiro(RJ): Escola de Enfermagem Anna Nery/ UFRJ; 2002. e ainda aumenta a possibilidade de acidentes de trabalho. Observa-se que os trabalhadores em geral não vêem o consumo de álcool como fator de risco, considerando, algumas vezes, como problema de outras pessoas apesar da sua própria exposição à substância etílica. Outros consideram o alcoolismo como risco de maior exposição aos acidentes de trabalho, levando-se em consideração a perda do domínio do próprio corpo na embriaguez. Outros o vêem como doença, embora encarada com certo preconceito.

Além disso, há também o fator agravante de o alcoolismo não ser uma doença de fácil identificação inicialmente, devido à sua fase de negação; isso faz com que os trabalhadores estejam mais suscetíveis a tornarem-se dependentes da substância e, conseqüentemente, mais expostos a riscos para acidentes de trabalho.

Diante da apresentação deste grave problema, concluo que medidas urgentes devem ser tomadas no sentido de prevenir o aparecimento de novos casos de alcoolismo, assim como atuar na promoção da saúde daqueles que já se encontram envolvidos com esta doença. Por se tratar de um problema de saúde pública, acredito que a prevenção deve começar por uma política governamental com campanhas informativas veiculadas através da mídia, devido ao seu largo alcance, com o objetivo de levar informações mais claras a respeito do alcoolismo e suas graves conseqüências.

Além disso, programas de prevenção devem ser elaborados desde a Rede Básica de Saúde, por se tratar da "porta de entrada" do atendimento em saúde, até as empresas nas quais atuam esses trabalhadores. Acredito que a aquisição de conhecimento pode levar a uma mudança de comportamento e, através dessa mudança, minimizar as graves conseqüências do alcoolismo, principalmente no que se refere ao risco para acidentes de trabalho.

9. Rogers B. Enfermagem do trabalho: conceitos e prática. Lisboa(PO): Lusociencia; 1994.

10. Donato M. 0 combate ao alcoolismo: contribuições para a prática do enfermeiro do trabalho. Rio de Janeiro(RJ): Fundação Gutenberg de Artes Gráficas; 1999.

11. Minayo MCS. 0 desafio do conhecimento: pesquisa qualitativa em saúde. $8^{\text {a }}$ ed. São Paulo (SP): Hucitec; 2004.

12. Leopardi MT. Metodologia da pesquisa científica. Santa Maria(RS): Palloti; 2001.

13. Gitlow SE, Peyser HS. Alcoolismo: um guia prático de tratamento. Porto Alegre(RS): Artes Médicas; 1991.

14. Dejours CA. Loucura do trabalho: estudo de psicopatologia do trabalho. São Paulo(SP): Cortez; 1992.

15. Carrillo PLL. Uso e abuso de álcool e outras drogas, ações de promoção e prevenção no trabalho: uma perspectiva na integração da enfermagem [dissertação de mestrado]. Rio de Janeiro(RJ): Faculdade de Enfermagem / UERJ; 2002. 